\title{
Salt-responsive genes in rice revealed by cDNA microarray analysis
}

\author{
Dai Yin $\mathrm{CHAO}^{1,3}$, Yong Hai LUO ${ }^{1,3}$, Min $\mathrm{SHI}^{1}$, Da LUO ${ }^{1,2}$, Hong Xuan LIN ${ }^{1,2, *}$ \\ ${ }^{1}$ National Key Laboratory of Plant Molecular Genetics, Shanghai Institute of Plant Physiology and Ecology, Shanghai \\ Institutes for Biological Sciences, Chinese Academy of Sciences, 300 Fenglin Road, Shanghai 200032, China, \\ ${ }^{2}$ SHARF Laboratory, Shanghai Institute of Plant Physiology and Ecology, Shanghai Institutes for Biological Sciences, \\ Chinese Academy of Sciences, 300 Fenglin Road, Shanghai 200032, China, \\ ${ }^{3}$ Graduate School of the Chinese Academy of Sciences (D.C.), 19 Yuquan Road, Beijing 100039, China
}

\begin{abstract}
We used cDNA microarrays containing $\sim 9,000$ unigenes to identify 486 salt responsive expressed sequence tags (ESTs) (representing 450 unigenes) in shoots of the highly salt-tolerant rice variety, Nona Bokra (Oryza sativa L. ssp. Indica $p v$. Nona). Some of the genes identified in this study had previously been associated with salt stress. However the majority were novel, indicating that there is a great number of genes that are induced by salt exposure. Analysis of the salt stress expression profile data of Nona provided clues regarding some putative cellular and molecular processes that are undertaken by this tolerant rice variety in response to salt stress. Namely, we found that multiple transcription factors were induced during the initial salt response of shoots. Many genes whose encoded proteins are implicated in detoxification, protectant and transport were rapidly induced. Genes supporting photosynthesis were repressed and those supporting carbohydrate metabolism were altered. Commonality among the genes induced by salt exposure with those induced during senescence and biotic stress responses suggests that there are shared signaling pathways among these processes. We further compared the transcriptome changes of the salt-sensitive cultivar, IR28, with that of Nona rice. Many genes that are salt responsive in Nona were found to be differentially regulated in IR28. This study identified a large number of candidate functional genes that appear to be involved in salt tolerance and further examination of these genes may enable the molecular basis of salt tolerance to be elucidated.
\end{abstract}

Keywords: cDNA microarray, rice, salt stress, signaling crosstalk, transcriptome.

\section{INTRODUCTION}

Salinity is one of the main abiotic stresses to plants, and is often at least partly responsible for low crop yields [1]. Thus, scientists have long sought to understand and improve the mechanisms of salt tolerance in crop plants. To date, multiple components of salt tolerance signaling in Arabidopsis have been identified through genetic, molecular and biochemical methods [2], and these molecules have been used to engineer salt tolerance in some plants.

*Correspondence: Hong Xuan LIN

Tel: +86-21-54924129; Fax: +86-21-54924015;

E-mail: hxlin@sippe.ac.cn,

Abbreviations: EST (expressed sequence tag); ROS (reactive oxygen species); RT-PCR (reverse transcription-polymerase chain reaction); SAM (significance analysis of microarrays, or shoot apical meristem); SIM (salt-induced microarray); TF (transcription factors); UTR (untranslated region).
For example, SOS1 overexpression was shown to increase salt tolerance in the same plant [3]. Another major breakthrough in salt tolerance research was the elucidation of the $\mathrm{CBF} / \mathrm{DREB}$ regulation pathway [4-7]. Under abiotic stress, the $C B F / D R E B$ and $A R E B$ transcription factors are rapidly induced, and are thus termed the "early-response genes". These factors bind the DRE or ABRE cis-elements found in downstream target genes, such as members of the LEA family, which are called the "delayed-response genes." Overexpression of the Arabidopsis CBF1/DREB $1 B$ or $C B F 3 / D R E B 1 A$ genes increased tolerance to salt, drought and other abiotic stresses in Arabidopsis, tomato and wheat [7-10], indicating that these theories and engineering strategies are viable and that Arabidopsis is a good model plant for salt tolerance research.

Comparatively less progress has been made in terms of understanding salt tolerance in rice, a model crop plant. Some rice homologs of known salt tolerance genes have 
been identified and examined, such as OSDREB1A that improved Arabidopsis salt tolerance when overexpressed [11]. In addition, some salt-tolerant rice lines have been generated by transgenic modulation of salt response gene expression. For example, introduction of the barley HVAI gene into rice under the control of the rice Act 1 promoter significantly increased rice tolerance to drought and salinity [12]. However, although these studies have provided good early clues as to the underlying mechanisms of salt tolerance, the precise signaling pathways remain unknown, largely because salt tolerance is a complex trait controlled by many quantitative trait loci (QTLs) [13]. In addition, the currently known components of salt tolerance do not form a complete picture. Thus, it is necessary to apply modern high throughput technologies, such as microarray analysis, for the efficient, large-scale identification of new genes related to salt tolerance [14-21].

Here, we used a cDNA microarray containing $\sim 9,000$ unigenes to monitor the expression profiles of rice shoots under salt stress, and to identify new salt response genes. We also compared the profiles of salt-tolerant (Nona) and -sensitive (IR28) rice varieties. Our results indicate that many genes, including some previously associated with plant salt tolerance, are differentially regulated in Nona and IR28 following salt stress. These genes may thus be good candidates for future engineering of salt-tolerant crops.

\section{MATERIALS AND METHODS}

\section{Plant growth and treatment}

The highly salt-tolerant rice variety, Nona Bokra (Oryza sativa, var. Indica), and the salt-susceptible variety, IR28 (O. sativa, var. Indica) were used in this study. The seeds were stimulated to break dormancy and germinated as previously described [13]. The uniformly germinated seeds were sown in 96-well plates from which the well bottoms had been removed. The plates were immersed in distilled water for $2 \mathrm{~d}$ at $30^{\circ} \mathrm{C}$, and then transferred to Yoshida's culture solution and grown under a 13-h light $\left(26^{\circ} \mathrm{C}\right) / 11$-h dark $\left(22^{\circ} \mathrm{C}\right)$ photoperiod (photo intensity $240 \mu \mathrm{m}$ photos $\mathrm{m}^{-2} \mathrm{~s}^{-1}$ ). Growth culture solution was renewed every $2 \mathrm{~d}$. After $12 \mathrm{~d}$ in culture, the seedlings were used for experiments.

On the salt treatment day, the seedlings in the salt stress treatment group were transferred into fresh culture solution with increased salinity $(140 \mathrm{mM} \mathrm{NaCl})$ after they turned to light period for $3 \mathrm{~h}$. Meanwhile, the culture solution for control seedlings was also renewed with normal culture solution.

\section{RNA isolation}

The aerial parts of treated and control seedlings were collected, and total RNAs were extracted for microarray hybridization, RTPCR and Northern blot analysis. For each sample, about 30 seedlings were pooled and immediately transferred into liquid nitrogen. Samples were then ground to a fine powder and extracted with the Trizol reagent (GIBCO BRL, USA), according to the manufacturer's instructions.

\section{Microarraypreparation}

The rice BiostarP-100s cDNA microarray (United Gene Holdings, Ltd., PRC), containing 10,060 sequences representing $~ 9000$ unigenes including novel, known and control genes, was used to identify saltregulated genes. Gene expression was examined at three time points after salt treatment ( $20 \mathrm{~min}, 3 \mathrm{~h}$ and $24 \mathrm{~h}$ ) corresponding to early transient, intermediate and late regulation. All the assays were replicated three times (two repetitions were that control was labeled with Cy5 and treatment was labeled with Cy3; the other repetition was reversely labeled). To control against circadian clock and developmental effects, isochronous seedlings grown in normal solution were used as controls at each time point.

The significantly regulated genes (see below) at each time point were selected for cluster analysis and for inclusion in the salt-induced-microarray (SIM). The SIM consisted of 486 significantly salt-regulated genes identified from the BiostarP-100s cDNA microarray, 69 house keeping genes used for normalization control, and 8 human-specific genes used as negative controls. The utilized genes were amplified by polymerase chain reaction (PCR) of the appropriate rice or human cDNA clones (provided by United Gene Holdings, Ltd., PRC) using T3 and T7 primers. After the resulting products were purified and confirmed by direct sequencing, the fragments were printed on slides using an OmniGrid printer (GeneMachine Co. Ltd., USA).

\section{Preparation of fluorescent probes and microarray hybridiza- tion}

RNA was fluorescence-labeled in the dark using a Fluorescence Labeling Kit (United Gene, Ltd., PRC). Total RNA (60 mg) from each pooled sample was reverse transcribed. The test RNA was labeled with Cy5-dCTP and the control RNA was labeled with Cy3dCTP; all reactions were done in the dark. Labeled targets were used for hybridization according the instructions supplied with the Hybridization Kit (United Gene Holdings, PRC). Slides were then washed, and the fluorescent signatures were scanned and captured using a ScanArray4000 Standard Biochip Scanning System (Packard Biochip Technologies, Inc., USA). Data were analyzed using the GenePix Pro 3.0 software (Axon Instruments, Inc., USA).

\section{Data filtration, statistical analysis and cluster analysis}

Signals with intensities below 200 were adjusted to 200 (designated as the background level). Spots with both channel intensities less than 800 , with 0 non-saturated pixels of one channel, with bad shape or severely contaminative were filtered out. The remaining spots were considered to be good spots and their raw signal intensity data were normalized according to the methods of total intensity normalization. Then cross-slide one-class $t$-test analysis was performed on the three replicates, and the P value was calculated with Stata statistics software (Stata Corporation, Taxas, USA). The ratio of Cy5 intensity versus Cy3 intensity was calculated for the ESTs that survived a $t$-test ( $5 \%$ significance). The genes with a ratio more than 2 or below 0.5 were considered to be regulated significantly by the salt treatment. However, genes with one fluorescent intensity signal below 800 were required to have a ratio over 2.5 or below 0.4 to be considered salt-regulated. For further analysis of these genes, the ratios were converted into $\log 2$ values and the standard deviations of the three repetitions were calculated. To compare the transcriptome differences between IR28 and Nona, a two-sample $t$ test analysis was performed. The $P$ values were calculated with Stata statistics software (Stata Corporation, Taxas, USA). 
To perform cluster analysis, the raw data were further managed as follows: Genes with standard deviations of $\log 2$ ratio below 0.4 were considered credible and their $\log 2$ values were averaged and used for cluster analysis. Genes with standard deviations equal to or greater than 0.4 were flagged as being potentially non-credible. However, if two of the three repetitions were consistent with each other (standard deviation of $\log 2$ values below 0.2 , and similar raw fluorescent intensities), the accordant values were considered credible and were averaged for further analysis. The flagged data were considered 'missing data' for cluster analyses. Finally, cluster analyses were performed with GeneMaths software (Applied Maths, Sint-MarternsLaterm, Belgium).

\section{Gene comparing and sequence alignment}

Genes and EST sequences that have previously been identified as salt responsive were found according to information [14-21]. The TIGR rice pseudomolecular database (ftp://ftp.tigr.org/pub/data/ Eukaryotic_Projects/o_sativa/annotation_dbs/) and the KOME fulllength cDNA database (http://cdna01.dna.affrc.go.jp/cDNA/) were also downloaded and used for reference. Unigene matches for the 486 identified ESTs (http://www.cell-research.com/200510/ EST_sequenses1.txt) were first found in the above databases by local BLAST (Basic Local Alignment Search Tool) searching. Matched unigenes for the previously identified rice genes were then found by using Blastn, while the homologues from previously identified genes from other plants were found by using tBlastx. Finally, the two results were compared; Microsoft Excel and Access software were employed to find those genes that were identical or homologous between this study and previous research.

\section{RT-PCR and RNA gel blot analysis}

The microarray results were confirmed by RT-PCR and RNA gel blot analysis. For RT-PCR, primers were designed to amplify specific regions of randomly selected genes. Samples were reverse transcribed using the Reverse Transcription System kit (Promega Corp, USA) according to the manufacturer's protocol, separated by electrophoresis and examined.

For RNA gel blot analysis, total RNA (20 $\mu \mathrm{g})$ from each sample was separated on $1.0 \%$ agarose-formaldehyde gels and transferred to hybond- $\mathrm{N}^{+}$(Amersham Pharmacia) membranes. The membranes were fixed at $80^{\circ} \mathrm{C}$ for $2 \mathrm{~h}$ and then hybridized overnight at $42^{\circ} \mathrm{C}$ with cDNA probes previously labeled with the Random Primer DNA Labeling Kit ver.2 (Takara, Japan). After hybridization, the membranes were washed twice in $2 \times \mathrm{SSC}$ and $0.5 \% \mathrm{SDS}$ for $10 \mathrm{~min}$ at room temperature, and twice in $0.5 \% \times \mathrm{SSC}$ and $0.1 \%$ SDS for $10 \mathrm{~min}$ at $42^{\circ} \mathrm{C}$. Finally, the membranes were exposed to $\mathrm{x}$-ray films at $-80^{\circ} \mathrm{C}$.

\section{RESULTS}

\section{Reproducibility of hybridizations and confirmation by RT-PCR and Northern b lotting}

To control against technical and biological errors, we performed homotypic hybridizations and hybridizations between two independent pooled samples under identical conditions, and then plotted raw signals and generated scatter plots to examine the consistency of our results (Fig. 1). Only 19 probes with low signal intensities fell outside of the range of 2.0-fold relative intensity differences between the two fluorescent dyes (data not shown), and most of the probes clustered tightly near the diagonal of the plot (Fig. 1A). These results revealed that our falsepositive rate was $<0.2 \%$ even after being screened only by a factor of 2 -fold. In terms of selecting significantly regulated genes across all three replications, the predicted false-positive rate was 8 spots per $10^{9}$. In contrast, we observed a higher variability between the two independent pooled samples (Fig. 1B). In this case, 36 probes fell outside the 2.0-fold standard (data not shown), and the scatter plot was slightly more dispersed (Fig. 1). These results indicate that differences among the samples could affect the results of the pooled samples. However, the signal intensities of most of the false-positive spots were less than 800 . Three of 36 false-positive spots in the independent experiment and 0 of 19 false-positives in the homotypic hybridization yielded double-fluorescence signal intensities over 800, and the 3 false-positive spots had ratios ranging from 0.46 to 0.49 . Furthermore, among those with one fluorescence signal intensity below 800 , only 4 ratio values were $<0.4$ or $>2.5$ (data not shown). These observations were used to establish criteria for our subsequent data management and statistical analyses.

To ensure that the statistical analysis applied in our screening of salt response genes was sufficiently stringent, we performed a one-class $t$-test analysis for three replicates, and then applied a 2 -fold or 2.5-fold criterion. This approach resulted in further screening of the genes that had been identified in the $t$-test analysis ( $5 \%$ significant level). And of the genes determined to be salt-responsive by our fluorescence analysis, $97.5 \%$ reached the $1 \%$ significance level and $\sim 90 \%$ reached the $0.5 \%$ level, providing further evidence that our methods yielded very few false positives.

To further validate the reliability of our microarray data, we performed RT-PCR and/or Northern blot analysis of 11 randomly selected genes. Five of these genes were tested by Northern blotting, four of which gave detectable signals. The results were in good agreements with the microarray data of the four genes [LIP9 (R0144F10), an unknown gene (R0540C06), a rice kinase (R0018F09) and a 6-phosphogluconolactonase-like protein (R0127E06)] (Fig. 2A), while we were unable to detect a signal for R0127E06 (data not shown). An examination of the raw signal intensities revealed that this gene is expressed at very low levels at all three tested time points (data not shown). For RT-PCR, seven genes were randomly selected, and specific primers were designed based on sequences in the 5'- or 3'-UTRs. Most of the tested genes showed good agreement between the RT-PCR and microarray results (Fig. 2B). Some inconsistencies were 

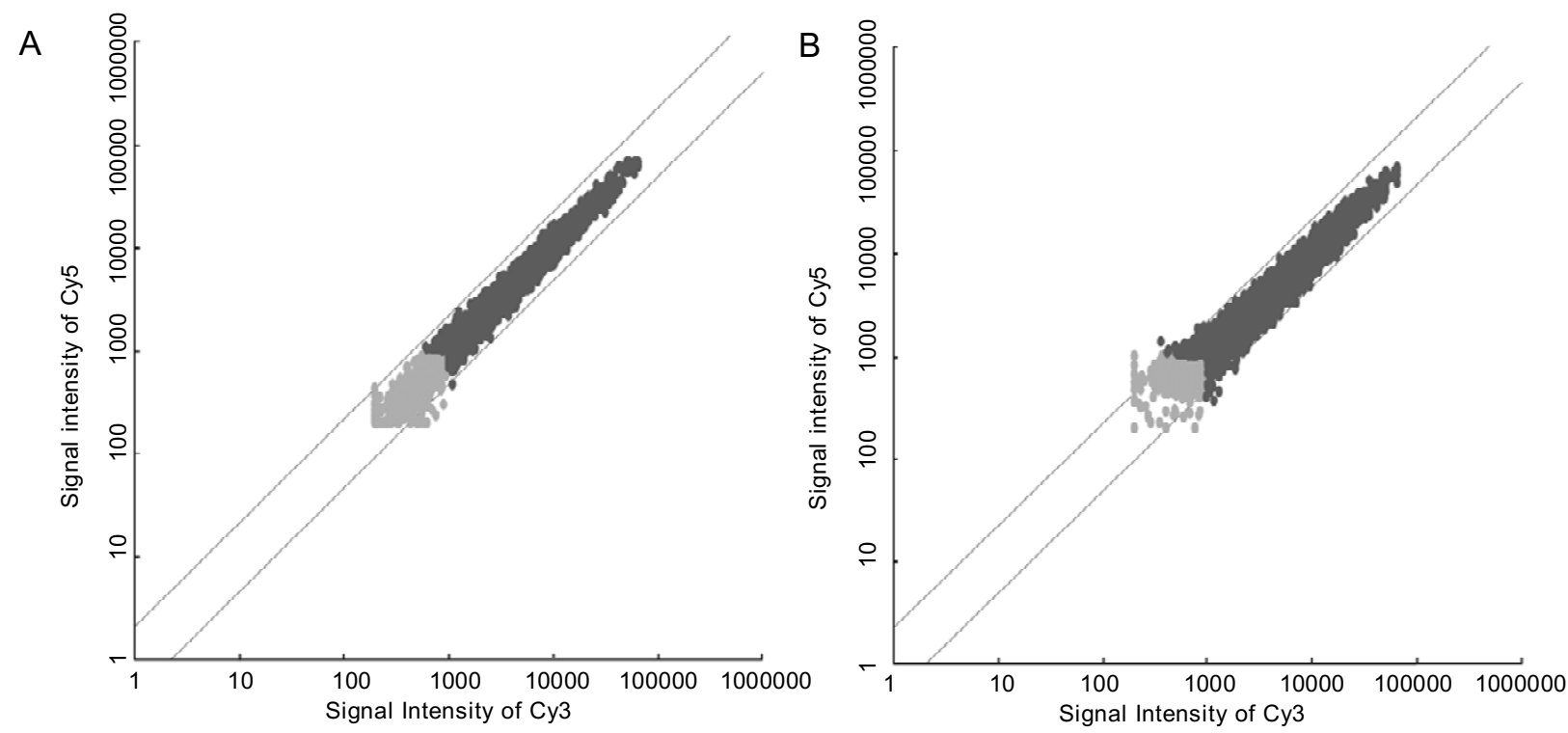

Fig. 1 Reproducibility of hybridizations and independent experiments. (A) Reproducibility of hybridizations. RNAs from the same pool were labeled with $\mathrm{Cy} 3$ and $\mathrm{Cy} 5$, respectively, and hybridized to the same microarray. A scatter plot comparing the log-10 raw fluorescent signal intensities of Cy3 and Cy5 is shown, indicating that $99.8 \%$ of the ESTs were within a 2-fold range and most of the variable ESTs had low signal intensities. (B) Reproducibility of independent experiments. RNAs from different pooled samples harvested under the same conditions at different times were labeled with $\mathrm{Cy} 3$ and $\mathrm{Cy} 5$, respectively, and hybridized to the same microarray. A scatter plot comparing the log-10 raw fluorescent signal intensities is shown.
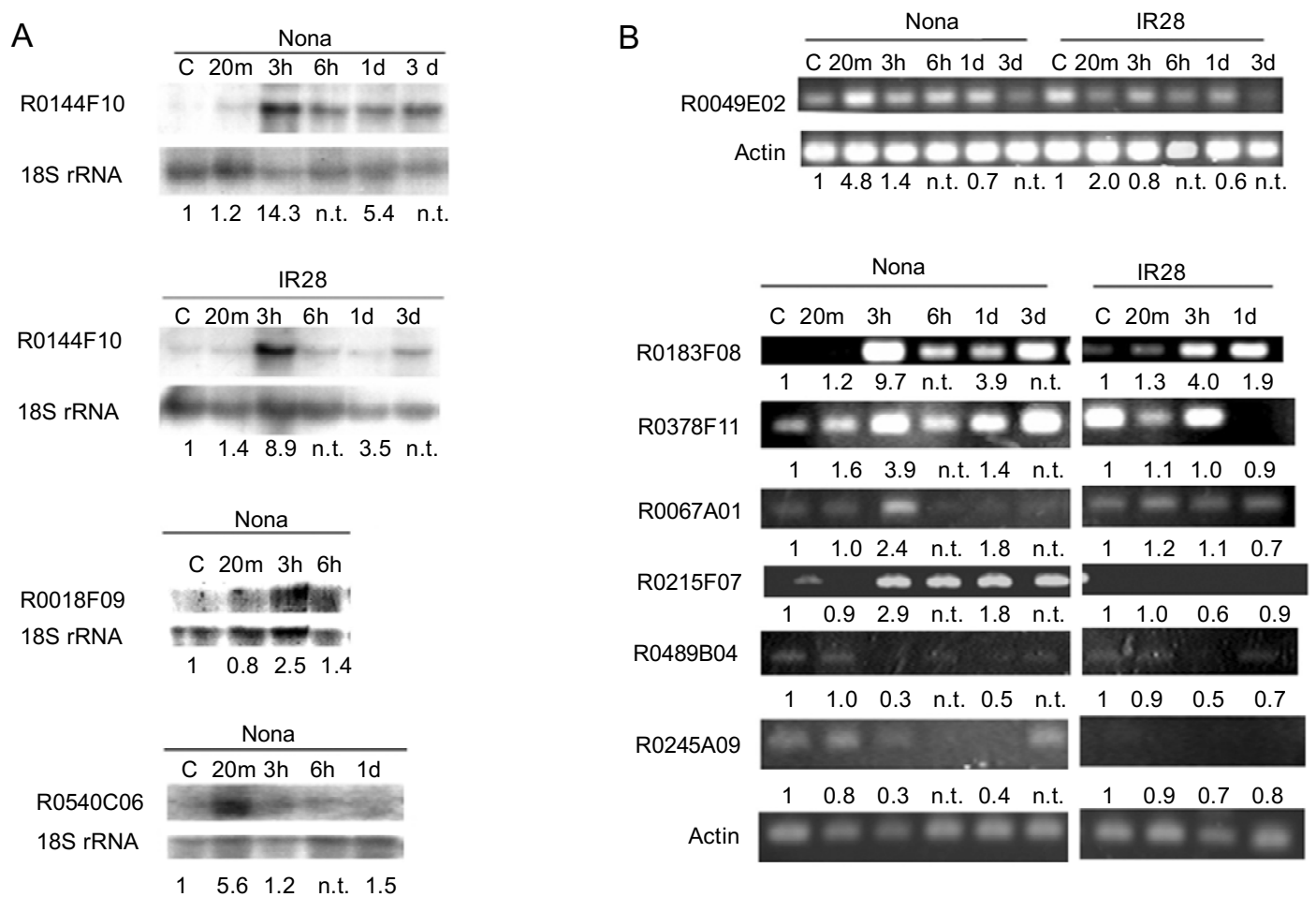

Fig. 2 Northern blotting and RT-PCR confirmation of microarray results. (A) Northern blotting was used to examine the expression of three genes in Nona and IR28 plants under salt stress. Each lane was loaded with $20 \mu \mathrm{g}$ total RNA; the corresponding microarray ratios are shown at the bottom. c, control; n.t., not detected. (B) RT-PCR was used to validate the microarray results in 7 genes. Each tested gene was RT-PCR amplified three separate times; representative examples are shown. The corresponding microarray ratios are shown at the bottom of each lane. c, control. 
noted, but this may be due to the sensitivity of the applied method. RT-PCR depends on high-quality template RNA that may be affected by extraction and storage, especially when the transcript level is low. In addition, both RT-PCR and microarray analysis are semiquantitative methods that may vary in opposite directions, creating slight inconsistencies.

\section{Approximately 450 unigenes were identified as being salt-responsive}

Using the BiostarP-100s rice cDNA microarray, we analyzed the rice shoot transcriptome of the salt-tolerant cultivar, Nona, at three time points following treatment with $140 \mathrm{mM} \mathrm{NaCl}$. In total, we identified 486 ESTs representing about 450 unigenes that were significantly regulated in Nona shoots $20 \mathrm{~min}, 3 \mathrm{~h}$ and/or $24 \mathrm{~h}$ after salt treatment. These results indicate that about $5 \%$ of all genes were transcriptionally altered in salt-stressed Nona shoots, a smaller proportion than the $8 \%$ previously identified in salt-stressed yeast [22-23] or the $11 \%$ reported in saltstressed maize [18].

To further characterize the identified genes, we used sequence alignment to compare those genes with previously identified salt-responsive genes. Among the 450 saltresponsive genes identified in the present study, 68 had been reported previously to be salt response genes in rice (Tab. 1) [14, 19], and 152 were homologues of genes that had been identified as salt-responsive in other plants, such as Arabidopsis, barley and maize (Tab. 1) [15-18, 20,
21]. After deducting overlapping genes, the identified group of genes included 175 genes $(\sim 40 \%)$ that had been previously associated with plant salt tolerance or salt stress responses, while the remaining $325(\sim 60 \%)$ represent novel candidate rice salt tolerance genes (Tab. 1). Among those novel candidate genes, 20 had no identifiable homologies to entries in the TIGR rice pseudomolecular database (ftp://ftp.tigr.org/pub/data/ Eukaryotic_Projects/o_sativa/annotation_dbs/) or the KOME full-length cDNA database (http://cdna01.dna. affrc.go.jp/cDNA/) (Tab. 2).

We performed hierarchical cluster analysis of our transcriptome data, which revealed that the identified ESTs could be classified into at least 5 distinct groups: early transient response genes (Group I), intermediate up-regulated genes (Group II), long term up-regulated genes (Group III), intermediate down-regulated genes (Group IV) and long term down-regulated genes (Group V) (Fig. 3). Here, 'intermediate' and 'long term' mean to response only at 3 $\mathrm{h}$ and to response till to $24 \mathrm{~h}$, respectively.

\section{Group I: The genes induced immediately after salt stressed were mainly those coding transcription fac- tors and kinases}

The early transient response cluster (Group I) contains 28 ESTs representing 26 unigenes (Tab. 2). This group includes most (28 of 30 ) of the ESTs that were significantly regulated after $20 \mathrm{~min}$ of salt treatment. And the remaining two were classified into Group III. Unlike the

Tab. 1 Comparison of salt response genes identified in this study with those in previous studies

\begin{tabular}{|c|c|c|c|c|c|c|c|c|c|c|}
\hline Species & Organism & $\begin{array}{l}\text { Overl } \\
\text { with }\end{array}$ & $\begin{array}{l}\text { lap ge } \\
\text { this } p\end{array}$ & & $\begin{array}{l}\text { Positive } \\
\text { genes/ESTs }\end{array}$ & $\begin{array}{l}\mathrm{NaCl} \\
\text { Conc. }\end{array}$ & Time course & Age & Microarray type & Report \\
\hline \multirow{5}{*}{ Arabidopsis } & whole plant & & & 39 & $194 /-$ & $250 \mathrm{mM}$ & $\begin{array}{l}1,2,5 \\
10,24 \mathrm{~h}\end{array}$ & 3 weeks & $7 \mathrm{k}$ cDNA microarray & [15] \\
\hline & whole plant & & & 11 & 44 & $250 \mathrm{mM}$ & $2 \mathrm{~h}$ & $3-4$ weeks & $7 \mathrm{k}$ cDNA microarray & {$[20]$} \\
\hline & cell culture & & & 11 & $81 /-$ & $100 \mathrm{mM}$ & $1,5 \mathrm{~h}$ & - & 7k cDNA microarray & {$[21]$} \\
\hline & Leaf & & & 29 & $214 /-$ & $100 \mathrm{mM}$ & $3,27 \mathrm{~h}$ & 7 days & 8100 genes Affy. Genechip & {$[16]$} \\
\hline & Root & & 152 & 69 & $415 /-$ & $100 \mathrm{mM}$ & $3,27 \mathrm{~h}$ & 7 days & 8100 genes Affy. Genechip & {$[16]$} \\
\hline \multirow[t]{2}{*}{ Barley } & Leaf & 175 & & 21 & $54 /-$ & $150 \mathrm{mM}$ & $24 \mathrm{~h}$ & 3 weeks & $1.4 \mathrm{k}$ cDNA microarray & {$[17]$} \\
\hline & Root & & & 2 & $19 /-$ & $150 \mathrm{mM}$ & $24 \mathrm{~h}$ & 3 weeks & $1.4 \mathrm{k}$ cDNA microarray & {$[17]$} \\
\hline Zea mays & Root & & & 68 & $472 / 916$ & $150 \mathrm{mM}$ & $1,3,6,12$ & 4 weeks & 7943 ESTs microarray & {$[18]$} \\
\hline \multirow[t]{2}{*}{ Rice } & root & & 68 & 42 & $214 / 253$ & $150 \mathrm{mM}$ & $\begin{array}{l}24,72 \mathrm{~h} \\
15 \mathrm{~min}, 1,3 \\
6,24,72 \mathrm{~h}\end{array}$ & $\begin{array}{l}\text { roots }=7 \mathrm{~cm} \\
\text { shoots }=10 \mathrm{~cm}\end{array}$ & 1.7k ESTs microarray & {$[14]$} \\
\hline & whole plant & & & 31 & $57 /-$ & $250 \mathrm{mM}$ & $5,10,24 \mathrm{~h}$ & 2 weeks & $1.7 \mathrm{k}$ cDNA microarray & [19] \\
\hline
\end{tabular}

\footnotetext{
${ }^{a}$ The right column shows numbers of genes which or which homologs were both identified in this paper and each previous report. These previous reports had also overlap genes with each other. Thus, the numbers in the middle column and the left column are smaller than the corresponding sum of data in the right column.
} 
Tab. 2 Categories of transcripts significantly regulated in salt-stressed Nona

\begin{tabular}{|c|c|c|c|c|c|c|c|c|c|c|c|c|c|c|c|c|}
\hline \multirow{2}{*}{$\begin{array}{l}\text { Functional } \\
\text { categories }\end{array}$} & \multicolumn{3}{|c|}{ Group I $^{\mathrm{a}}$} & \multicolumn{3}{|c|}{ Group II ${ }^{b}$} & \multicolumn{3}{|c|}{ Group III $^{\mathrm{c}}$} & \multicolumn{3}{|c|}{ Group IV $^{\mathrm{d}}$} & \multicolumn{3}{|c|}{ Group $V^{\mathrm{e}}$} & \multirow[b]{2}{*}{ Total } \\
\hline & $\mathrm{No}^{\mathrm{f}}$ & $(\%)^{g}$ & $\%^{\mathrm{h}}$ & No & $(\%)$ & $\%$ & $\mathrm{No}$ & $(\%)$ & $\%$ & No & (\%) & $\%$ & No & $(\%)$ & $\%$ & \\
\hline Unknown or & 10 & 35.71 & 7.75 & 82 & 29.50 & 63.57 & 13 & 23.21 & 10.08 & 7 & 12.28 & 5.43 & 17 & 25.37 & 13.18 & 129 \\
\hline \multicolumn{17}{|l|}{ Unclassified } \\
\hline Metabolism & 1 & 3.57 & 0.85 & 65 & 23.38 & 55.08 & 8 & 14.29 & 6.78 & 20 & 35.09 & 16.95 & 24 & 35.82 & 20.34 & 118 \\
\hline Kinase & 5 & 17.86 & 15.63 & 17 & 6.12 & 53.13 & 3 & 5.36 & 9.38 & 3 & 5.26 & 9.38 & 4 & 5.97 & 12.50 & 32 \\
\hline Transcription & 8 & 28.57 & 25.00 & 18 & 6.47 & 56.25 & 4 & 7.14 & 12.50 & 0 & 0.00 & 0.00 & 2 & 2.99 & 6.25 & 32 \\
\hline Signal transduction & 1 & 3.57 & 4.35 & 14 & 5.04 & 60.87 & 3 & 5.36 & 13.04 & 2 & 3.51 & 8.70 & 3 & 4.48 & 13.04 & 23 \\
\hline $\begin{array}{l}\text { Cell defense or } \\
\text { antioxditant }\end{array}$ & 1 & 3.57 & 1.96 & 37 & 13.31 & 72.55 & 7 & 12.50 & 13.73 & 1 & 1.75 & 1.96 & 5 & 7.46 & 9.80 & 51 \\
\hline Cellular transport & 0 & 0.00 & 0.00 & 17 & 6.12 & 60.71 & 2 & 3.57 & 7.14 & 6 & 10.53 & 21.43 & 3 & 4.48 & 10.71 & 28 \\
\hline No hits & 1 & 3.57 & 5.00 & 9 & 3.24 & 45.00 & 5 & 8.93 & 25.00 & 3 & 5.26 & 15.00 & 2 & 2.99 & 10.00 & 20 \\
\hline Photosynthesis & 0 & 0.00 & 0.00 & 0 & 0.00 & 0.00 & 1 & 1.79 & 20.00 & 3 & 5.26 & 60.00 & 1 & 1.49 & 20.00 & 5 \\
\hline RNA process & 0 & 0.00 & 0.00 & 1 & 0.36 & 11.11 & 5 & 8.93 & 55.56 & 3 & 5.26 & 33.33 & 0 & 0.00 & 0.00 & 9 \\
\hline Other & 1 & 3.57 & 2.56 & 18 & 6.47 & 46.15 & 5 & 8.93 & 12.82 & 9 & 15.79 & 23.08 & 6 & 8.96 & 15.38 & 39 \\
\hline Total & 28 & 100 & 5.76 & 278 & 100 & 57.20 & 56 & 100 & 11.52 & 57 & 100 & 11.73 & 67 & 100 & 13.79 & 486 \\
\hline
\end{tabular}

${ }_{\mathrm{a}-\mathrm{e}}$ Early transient response ESTs, intermediate unregulated ESTs, long term unregulated ESTs, intermediate downregulated ESTs and long term down regulated ESTs.

${ }^{\mathrm{f}}$ Number of ESTs.

${ }^{\mathrm{g}}$ Percentage of the Group.

${ }^{\text {h }}$ Percentage of the total functional category.

The bold numbers are the data referred in text

previously reported up- and down-regulations of early responsive salt genes in the roots of a salt-tolerant rice line [14], all of the Group I genes in Nona shoots were upregulated (Suppl. 1, http://www.cell-research.com/ 200510/supplemental_table1.xls). Within this cluster, the largest functional category of identified genes (not counting the unclassified proteins) was the transcription regulator category, which comprised $28.57 \%$ of the Group I genes (Tab. 2). This category contains eight ESTs (7 unigenes) encoding transcription factors (TFs) or TF-related factors such as a calmodulin-binding transcription factor, a PHD-finger, a Zinc finger, a NAC transcription factor and other DNA-binding proteins (Suppl. 1). Among them, the NAC transcription factor had been previously associated with dehydration [24], while the others are newly identified as salt early transient response TFs.

The second main functional category of identified early salt responsive genes contains the kinases, comprising 5 ESTs representing 4 unigenes (Tab. 2). Of these, OsCDPK7 (R0157C06 and R0274A08) was shown to be transiently induced in stressed plant organs [14, 25], and its overexpression increased rice tolerance to salt stress $[26$, 27]. In contrast, the other three kinase genes were newly identified as salt induced genes.
Groups II and III: Many damage control or repair, growth inhibition and ion and osmotic homeostasis genes were up-regulated during the intermediate and long-term periods

Of the 334 ESTs significantly up-regulated in Nona plants after 3 and $24 \mathrm{~h}$ of salt treatment (Suppl. 1), 278 were clustered into Group II, which is the largest cluster, containing $57.20 \%$ of all significantly regulated ESTs (Tab. 2). In Group II, the largest identified functional category (not including the unclassified genes) comprised the metabolism-related genes. Of the total ESTs in Group II, 65 (23.38\%) corresponded to metabolic enzymes (Tab. 2), some of which have also been implicated in various detoxification pathways. In addition, multiple putative and/or known cell senescence genes clustered into this category, including cysteine protease (R0049D05 and R0127B07), asparagine synthase (R0169E12 and R0577D11), nuclease (R0350G04) and P450 (R0063A10). Interestingly, senescence-related genes were also found Group I, Group III and other categories of Group II. These included aspartic proteinase (R0008B09 and R0010F11), ClpC protease (R0386F08) and type 1 metallothionein (R0058B01) in Group III, NAD-dependent malate dehydrogenase (R0166E11) in Group I and polyubiquitin (R0373A03) in 
Group II. These results seem to indicate that the senescence pathways may be involved in the rice salt stress response.

The second largest identified protein class in Group II included the cell defense and detoxification genes, which contained some genes that overlapped into the metabolic category. The cell defense and detoxification category of Group II contained 37 members (13.31\% of Group II), accounting for $72.55 \%$ of all cell defense and detoxification ESTs identified in our study (Tab. 2). This category included four different types of genes that function damage control or repair: 1) those involved in removing ROS and other stress-induced toxins, included antioxidant enzymes such as glutathione reductase (R0150D06), dehydroascorbate reductase (R0155B11) and phospholipid hydroperoxide glutathione peroxidase (R0517A08); 2) those

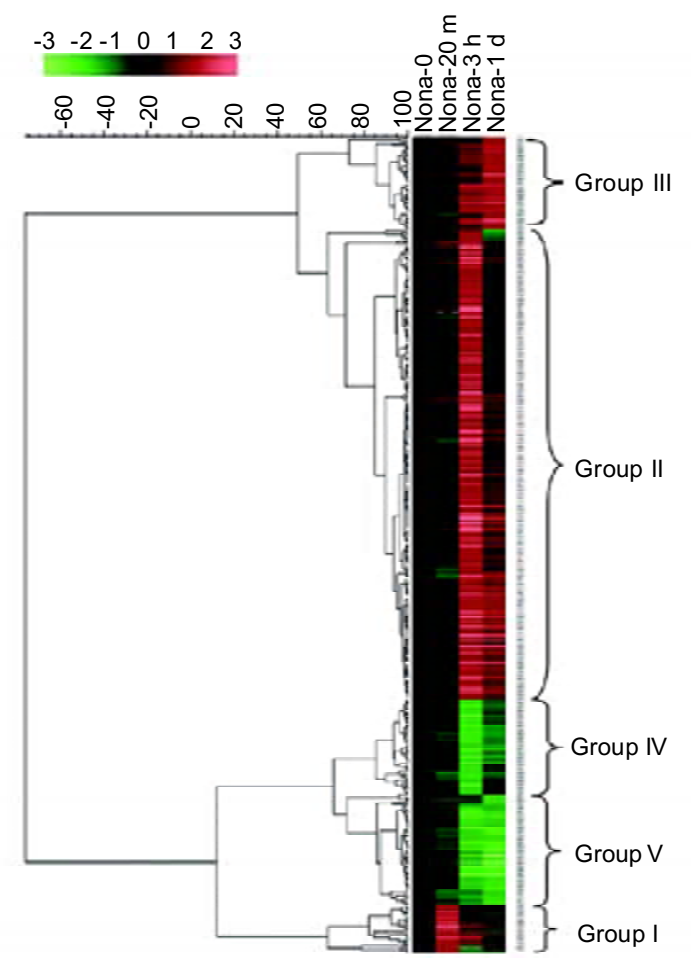

Fig. 3 Cluster analysis of ESTs significantly regulated in Nona shoots after salt treatment. The log-2 ratio values of 486 ESTs significantly regulated by salt stress were used for hierarchical cluster analysis with the GeneMaths software package. The red represents up-regulated genes; the green represents down-regulated genes; the black represents un-regulated genes; and the blanks represent missing data. Five distinct groups were distinguished: the early transient response genes (Group I), the intermediate up-regulated genes (Group II), the long term up-regulated genes (Group III), the intermediate downregulated genes (Group IV) and the long term down-regulated genes (Group V). The details of the gene annotation shown on the right are provided in Suppl. 1.

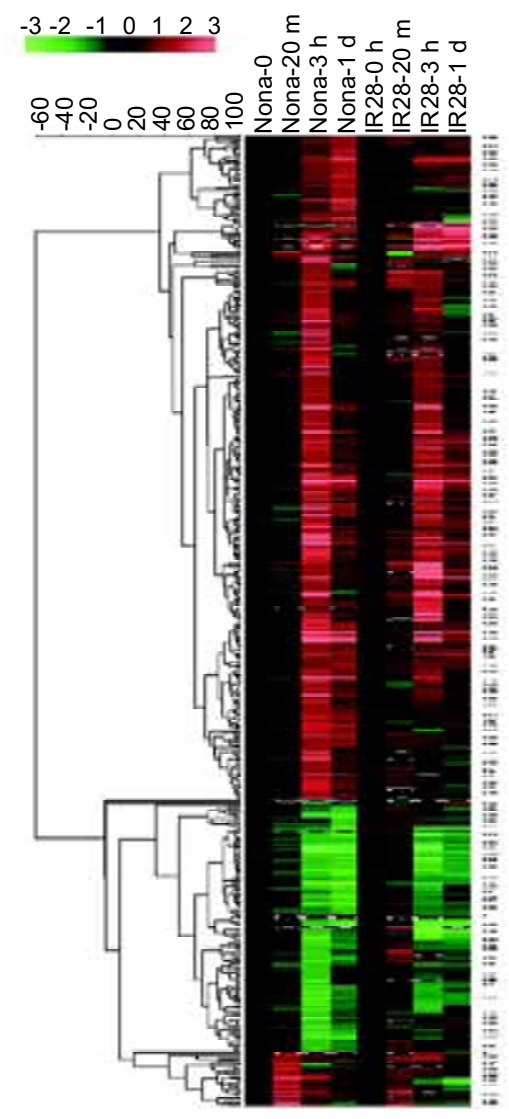

Fig. 4 Comparison of salt response gene expression in salt-stressed Nona and IR2 8 plants using hierarchical cluster analysis. The log-2 ratio values of salt response ESTs were used for hierarchical cluster analysis with the GeneMaths software package. The red represents up-regulated genes; the green represents down-regulated genes; the black represents un-regulated genes, and the blanks represent missing data. The details of the gene annotation shown on the right are provided in Suppl. 2.

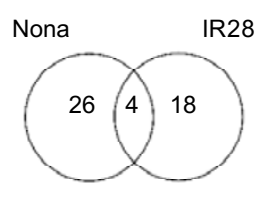

$20 \mathrm{~min}$

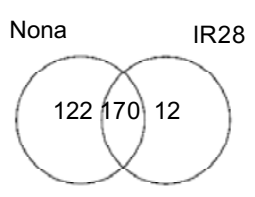

$3 \mathrm{~h}$

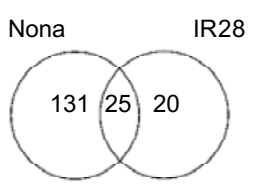

$24 \mathrm{~h}$
Fig. 5 Venn diagrams comparing salt response gene expression in Nona and IR28. The number of genes with altered expression in both Nona and IR28 at each time point is displayed in the intersections between the circles. The number of genes with altered expression in either Nona or IR28 is shown in the appropriate circle, such that the specific and shared genes in each circle equals the number of saltresponsive genes seen in the designated plant line at the indicated time point. $20 \mathrm{~min}, 3 \mathrm{~h}$ and $24 \mathrm{~h}$ indicate genes found to be expressionally altered $20 \mathrm{~min}, 3 \mathrm{~h}$ and $24 \mathrm{~h}$, respectively, after $\mathrm{NaCl}$ treatment. 
functioning in repair, including the heat shock (DnaJ and Clp) and DNA repair proteins; 3 ) those acting to maintain osmotic balances or homeostasis, including genes encoding three LEA family proteins, eight trehalose synthesisrelated enzymes and a phosphomannomutase; and 4) the disease resistance-like genes and other stress-induced genes, included four resistance protein genes (R0021A12, R0177A06, R0310H01 and R0523H02) and the chitinase gene (R0001C04).

Further examination of the genes classified into Group II suggested that signal transduction and ion transport were activated during the intermediate time period of salt stress in Nona rice. Group II included 14 signal transduction ESTs, comprising $60.87 \%$ of the total salt-responsive signal transduction molecules identified in our work (Tab. 2). These included three phosphatase 2Cs (Suppl. 1), homologs of which have been associated with abiotic stress signaling in Arabidopsis [28-30]. Interestingly, two ethylene insensitive 3 (ENI3) ESTs and two sensory transduction histidine kinase were also contained in Group II, along with 17 transport molecules $(60.71 \%$ of all transport molecules identified in this work) and 11 members related to ion transport (Suppl. 1).

Group III contained only 56 members (Tab. 2), indicating that most of the up-regulated genes were transiently induced. The largest identified category in Group III was that containing the metabolic enzymes, which had 8 members and comprised $14.29 \%$ of Group III. This category included genes encoding two aspartic proteinases, which could also be involved in cell senescence. The defense or detoxification category contained 7 members $(12.50 \%$ of Group III) including two glyoxalases, two heat shockrelated proteins (a DnaJ-related protein and a ClpC protease) and several other well-document salt induced genes such as osr40c1, rgMT-1 and SalT (Suppl. 1). The glyoxalase genes are vital to plant salt tolerance [31], and the expression of Glys in Arabidopsis is controlled by transcription factors of the NAC family [24]. In support of this, we identified a NAC transcription factor in Group II and a NAC binding motif (CACG) in the upstream sequence of our identified Glys.

\section{Groups IV and V: Photosynthesis and carbohydrate synthesis genes were down-regulated during the in- termediate and long-term time periods}

The down-regulated groups were dominated by metabolic genes, which comprised $35.09 \%$ and $35.82 \%$ of Groups IV and V, respectively (Tab. 2). Many of these genes encode enzymes responsible for catalyzing carbohydrate metabolism (Suppl. 1), perhaps leading to accumulation of osmolytes, energy or materials during the salt stress response. For example, down-regulation of the two
GDP-mannose dehydrogenase ESTs (R0489B04 and R0605A10, Group IV) could contribute to the accumulation of mannitol, as could down-regulation of the seven sucrose synthase transcripts identified in Group V [32].

The relatively smaller photosynthesis category contained only 5 members ( $1 \%$ of all 486 ESTs), four of which were down-regulated over the intermediate or long- term (Tab. 2). This observation seems to indicate that salt stress decreases photosynthesis is not only due to physical damage, but also results of the gene regulation.

\section{The salt-response transcriptomes differ in salt-toler- ant and salt-responsive rice shoots}

To compare the transcriptional regulation of salt-hypersensitive and -tolerant varieties, we investigated the expression pattern in salt-stressed IR28 of those genes identified in Nona shoot using the salt-induced microarray (SIM) derived from the BiostarP-100s rice cDNA microarray (see Materials and Methods). We found that although the expression patterns of many genes were similar in Nona and IR28 shoots, $69.3 \%$ of the salt-responsive ESTs identified in Nona were more or less differentially $(t$-test $P<0.05)$ expressed in IR28 at one or more time points (Fig. 4; Suppl. 2, http://www.cell-research.com/ 200510/supplemental_table2.xls). Interestingly, $60.7 \%$ of Group I and 65.9\% of Group III and Group V genes were differentially regulated (by a factor of 1.5 -fold or more) at $20 \mathrm{~min}$ and $24 \mathrm{~h}$ after salt treatment, respectively, while only $51 \%$ of Groups II and IV were differentially regulated at $3 \mathrm{~h}$. Similarly, when we compared the common significant-response genes (those showing $>2.0$-fold changes and surviving the statistical analysis) we found that Nona and IR 28 shared more differentially regulated genes at $20 \mathrm{~min}$ and $24 \mathrm{~h}$ than at $3 \mathrm{~h}$ (Fig. 5). Our results are comparable to a previous study comparing expression patterns in the roots of salt-stressed Pokkali and IR29 [14], which also found that the two varieties shared fewer response genes at 3 and $6 \mathrm{~h}$ post-treatment than at the $1 \mathrm{~h}$ time point.

We identified 81 ESTs that were significantly differentially regulated (the ratio of the regulation ratio in Nona vs that in IR2 8 was $>2.0$ or $<0.5$ fold, and the difference between Nona and IR28 reached the 5\% significant level) between salt-stressed Nona and IR28 shoots (Tab. 3), and found that they covered all functional categories. Among those significantly-differentially-regulated ESTs, 23 functioned metabolism, 9 functioned Cell Defense or antioxditant, 8 functioned kinases and 5 were novel ESTs (no hits). Interestingly, almost all of those very-differentially-regulated ESTs were weakly or not induced or repressed in salt-stressed IR28 shoots comparing to that in Nona (Tab. 3). Some of these weakly/not-induced genes 
Tab. 3 ESTs with significantly differential regulation pattern in Nona and IR28

\begin{tabular}{|c|c|c|c|c|c|c|c|c|c|c|}
\hline \multirow[t]{2}{*}{ Clone ID } & \multirow[t]{2}{*}{ Annotation } & \multicolumn{3}{|c|}{$\operatorname{IR} 28^{\mathrm{a}}$} & \multicolumn{3}{|c|}{ Nona/IR $28^{\mathrm{b}}$} & \multicolumn{3}{|c|}{$P$ value ${ }^{\mathrm{c}}$} \\
\hline & & $20 \mathrm{~min}$ & $3 \mathrm{~h}$ & $24 \mathrm{~h}$ & $20 \mathrm{~min}$ & $3 \mathrm{~h}$ & $24 \mathrm{~h}$ & $20 \mathrm{~min}$ & $3 \mathrm{~h}$ & $24 \mathrm{~h}$ \\
\hline \multicolumn{11}{|l|}{ Group I } \\
\hline R0049E02 & trehalose-6-phosphate phosphatase & 1.91 & 0.75 & 0.47 & 2.46 & 1.83 & 1.45 & 0.0369 & 0.0678 & 0.3136 \\
\hline R0274A08 & OsCDPK7 & 1.31 & 0.78 & 0.44 & 2.36 & 3.27 & 2.71 & 0.0033 & 0.0004 & 0.0229 \\
\hline R0166E11 & $\begin{array}{l}\text { chloroplast NAD-dependent malate } \\
\text { dehydrogenase }\end{array}$ & 1.01 & 1.11 & 1.14 & 2.28 & 0.41 & 0.69 & 0.0021 & 0.0008 & 0.0083 \\
\hline R0133G06 & $\begin{array}{l}\text { putative calmodulin-binding } \\
\text { transcription factor }\end{array}$ & 1.35 & 1.00 & 0.67 & 2.13 & 1.24 & 2.13 & 0.0012 & 0.0325 & 0.1195 \\
\hline $\mathrm{R} 0072 \mathrm{H} 01$ & expressed protein & 0.95 & 2.68 & 1.42 & 2.93 & 0.47 & 0.72 & 0.0035 & 0.0017 & 0.1381 \\
\hline R0074F07 & hypothetical protein & 0.50 & 1.31 & 1.75 & 5.24 & 1.05 & 0.75 & 0.0003 & 0.6284 & 0.0505 \\
\hline $\mathrm{R} 0511 \mathrm{C} 07$ & expressed protein & 1.39 & 0.95 & 0.68 & 2.01 & 1.48 & 1.83 & 0.0015 & 0.0002 & 0.0753 \\
\hline \multicolumn{11}{|l|}{ Group II } \\
\hline R0183F08 & aldehyde dehydrogenase & 1.18 & 3.76 & 2.77 & 0.99 & 2.55 & 1.41 & 0.9237 & 0.001 & 0.297 \\
\hline $\mathrm{R} 0251 \mathrm{~F} 07$ & PB1 domain, putative & 0.96 & 0.53 & 0.70 & 0.91 & 5.46 & 2.53 & 0.2105 & 0 & 0.0134 \\
\hline R0327F08 & DnaJ domain, putative & 1.54 & 4.72 & 3.05 & 0.74 & 0.43 & 0.45 & 0.5281 & 0.0387 & 0.0826 \\
\hline R0135B07 & aldehyde dehydrogenase & 1.27 & 3.66 & 2.64 & 1.04 & 2.60 & 1.44 & 0.6659 & 0.0002 & 0.1751 \\
\hline R0384A06 & Eukaryotic phosphomannomutase & 1.01 & 0.98 & 0.84 & 1.10 & 2.10 & 1.65 & 0.4843 & 0.0008 & 0.0149 \\
\hline $\mathrm{R} 0067 \mathrm{~A} 01$ & UDP-sugar transporter sqv-7 & 1.09 & 0.99 & 0.69 & 0.94 & 2.43 & 2.64 & 0.6299 & 0.0007 & 0.0002 \\
\hline R0129E03 & mitochondrial carrier protein, putative & 1.27 & 1.09 & 0.95 & 0.81 & 2.00 & 1.41 & 0.0266 & 0.0054 & 0.1921 \\
\hline R0375E06 & major facilitator superfamily protein & 2.00 & 0.77 & 1.06 & 0.54 & 3.46 & 1.11 & 0.0155 & 0.0029 & 0.5708 \\
\hline R0018F09 & protein kinase homolog - rice & 1.65 & 5.10 & 2.57 & 0.49 & 0.48 & 0.55 & 0.0017 & 0.0457 & 0.0466 \\
\hline R0022G09 & Protein kinase domain, putative & 1.73 & 1.62 & 0.88 & 0.47 & 2.11 & 1.61 & 0.0079 & 0.0012 & 0.1138 \\
\hline R0341A11 & AY062655 diacylglycerol kinase & 1.36 & 1.21 & 0.82 & 1.12 & 2.11 & 1.43 & 0.672 & 0.0051 & 0.3573 \\
\hline R0002D02 & pyrrolidone-carboxylate peptidase & 0.86 & 1.72 & 1.29 & 1.34 & 2.46 & 1.65 & 0.1198 & 0.0003 & 0.0001 \\
\hline R0014H10 & acetyl-CoA acyltransferases & 1.02 & 1.65 & 1.53 & 1.14 & 2.20 & 1.09 & 0.2173 & 0.0027 & 0.4403 \\
\hline R0020H08 & Oryza sativa 3-ketoacyl-CoA thiolase & 0.91 & 1.67 & 1.30 & 1.57 & 2.07 & 1.36 & 0.0058 & 0.0004 & 0.0008 \\
\hline R0031E06 & acid phosphatase & 1.01 & 1.12 & 1.21 & 1.01 & 2.20 & 1.82 & 0.9669 & 0.0006 & 0.0137 \\
\hline R0101F04 & $\begin{array}{l}\text { probable beta-alanine-pyruvate } \\
\text { aminotransferase }\end{array}$ & 1.14 & 2.91 & 2.75 & 0.98 & 2.31 & 1.01 & 0.8586 & 0.0131 & 0.9512 \\
\hline R0109A02 & fumarylacetoacetase & 1.05 & 1.33 & 1.49 & 0.91 & 2.08 & 1.36 & 0.2355 & 0.0038 & 0.2611 \\
\hline R0233F07 & amine oxidase & 1.75 & 9.06 & 2.91 & 0.86 & 0.34 & 0.52 & 0.3839 & 0.0056 & 0.0713 \\
\hline $\mathrm{R} 0252 \mathrm{E} 02$ & Pyrrolidone-carboxylate peptidase & 0.89 & 1.03 & 0.55 & 1.01 & 2.08 & 1.89 & 0.9766 & 0.0008 & 0.0317 \\
\hline R0356A09 & GDSL-like Lipase/Acylhydrolase & 1.04 & 1.01 & 0.83 & 0.91 & 2.16 & 1.93 & 0.3249 & 0.0001 & 0.0015 \\
\hline R0481A03 & $\begin{array}{l}\text { Beta-ketoacyl synthase, N-terminal } \\
\text { domain }\end{array}$ & 1.19 & 0.84 & 1.08 & 0.97 & 3.07 & 1.30 & 0.676 & 0.0159 & 0.221 \\
\hline R0539C11 & Similar to lysine-ketoglutarate reductase & 1.26 & 3.05 & 2.33 & 0.88 & 2.14 & 1.41 & 0.0909 & 0.0034 & 0.3636 \\
\hline $\mathrm{R} 0606 \mathrm{C} 07$ & $\begin{array}{l}\text { arabinoxylan arabinofuranohydrolase } \\
\text { isoenzyme }\end{array}$ & 1.28 & 1.46 & 1.04 & 0.80 & 2.71 & 2.10 & 0.4844 & 0.0234 & 0.0025 \\
\hline R0597D03 & no hits & 1.11 & 0.93 & 0.76 & 1.00 & 2.20 & 1.95 & 0.9698 & 0.0062 & 0.0157 \\
\hline R0159B12 & mitochondrial precursor & 0.98 & 1.04 & 0.88 & 1.08 & 2.04 & 2.00 & 0.5877 & 0.0017 & 0.0026 \\
\hline R0139G04 & ribosomal protein L28 & 1.64 & 1.41 & 1.34 & 0.64 & 2.64 & 1.82 & $\mathrm{M}^{\mathrm{d}}$ & 0.0117 & 0.0341 \\
\hline $\mathrm{R} 0074 \mathrm{C} 12$ & IQ calmodulin-binding motif, putative & 1.16 & 1.04 & 0.91 & 0.90 & 2.03 & 1.99 & 0.3715 & 0.0002 & 0.0007 \\
\hline R0507D08 & Protein phosphatase $2 \mathrm{C}$, putative & 0.98 & 0.94 & 0.80 & 1.25 & 2.17 & 1.56 & 0.2311 & 0.0002 & 0.0744 \\
\hline R0151G10 & Zinc finger, $\mathrm{C} 2 \mathrm{H} 2$ type, putative & 1.01 & 0.93 & 0.76 & 1.14 & 2.33 & 1.95 & 0.3792 & 0 & 0.0035 \\
\hline R0092E04 & F-box domain, putative & 2.17 & 1.62 & 0.99 & 0.36 & 2.04 & 2.43 & 0.0229 & 0.0677 & 0.0036 \\
\hline R0244H09 & expressed protein & 1.67 & 1.47 & 0.86 & 0.51 & 2.45 & 1.47 & 0.1522 & 0.0004 & 0.1279 \\
\hline R0343D01 & expressed protein & 2.77 & 5.17 & 1.14 & 0.62 & 0.44 & 1.18 & 0.0244 & 0.0152 & 0.6318 \\
\hline R0357A04 & unknow protein & 2.08 & 0.96 & 0.81 & 0.57 & 2.58 & 1.97 & 0.2374 & 0.0001 & 0.0096 \\
\hline R0378F11 & expressed protein & M & 0.90 & 0.87 & M & 4.32 & 1.65 & M & 0.0002 & 0.0284 \\
\hline R0381H09 & expressed protein & 1.48 & 1.08 & 0.85 & 0.72 & 2.73 & 2.23 & 0.0553 & 0.0054 & 0.0008 \\
\hline R0521H01 & expressed protein & 1.43 & 1.55 & 1.18 & 0.53 & 2.11 & 1.29 & M & 0.0108 & 0.3812 \\
\hline
\end{tabular}


Tab. 3 ESTs with significantly differential regulation pattern in Nona and IR28 (continued)

\begin{tabular}{|c|c|c|c|c|c|c|c|c|c|c|}
\hline \multirow[t]{2}{*}{ Clone ID } & \multirow[t]{2}{*}{ Annotation } & \multicolumn{3}{|c|}{$\operatorname{IR} 28^{\mathrm{a}}$} & \multicolumn{3}{|c|}{ Nona/IR28 ${ }^{\mathrm{b}}$} & \multicolumn{3}{|c|}{$P$ value $^{\mathrm{c}}$} \\
\hline & & $20 \mathrm{~min}$ & $3 \mathrm{~h}$ & $24 \mathrm{~h}$ & $20 \mathrm{~min}$ & $3 \mathrm{~h}$ & $24 \mathrm{~h}$ & $20 \mathrm{~min}$ & $3 \mathrm{~h}$ & $24 \mathrm{~h}$ \\
\hline \multicolumn{11}{|l|}{ Group III } \\
\hline $\mathrm{R} 0005 \mathrm{C} 01$ & glyoxalase & 1.09 & 0.76 & 0.86 & 1.39 & 2.00 & 2.38 & 0.0011 & 0.0005 & 0.0024 \\
\hline R0123D10 & lectin-like protein (SalT) & 1.68 & 7.89 & 17.27 & 0.63 & 0.14 & 0.13 & 0.0316 & 0.0005 & 0.0086 \\
\hline R0386F08 & Spinacia oleracea ClpC protease (clpC) & 1.04 & 1.07 & 0.89 & 1.10 & 1.82 & 2.55 & 0.2567 & 0.0003 & 0.0027 \\
\hline $\mathrm{r} 0548 \mathrm{a} 06$ & Eukaryotic protein kinase domain & 1.56 & 1.16 & 0.81 & 0.80 & 1.88 & 2.79 & 0.0501 & 0.0026 & 0.0008 \\
\hline R0067H09 & Haynaldia villosa clone kong2 8 mRA & 0.97 & 1.25 & 0.29 & 0.97 & 2.08 & 11.79 & 0.8568 & 0.0011 & 0 \\
\hline R0146C12 & CTP:phosphocholine cytidylyltransferase & 0.99 & 1.05 & 1.02 & 0.95 & 1.33 & 2.06 & 0.6035 & 0.0191 & 0.0013 \\
\hline R0183A08 & $\begin{array}{l}\text { NADP-ME2 mRNA for NADP } \\
\text { dependent malic enzyme }\end{array}$ & 1.01 & 0.65 & 0.49 & 1.12 & 1.41 & 4.23 & 0.3303 & 0.0286 & 0.0002 \\
\hline R0052H06 & no hits & 0.97 & 1.10 & 0.91 & 1.23 & 1.30 & 2.50 & 0.0627 & 0.1853 & 0.0007 \\
\hline R0130C10 & no hits & 0.86 & 1.09 & 0.82 & 0.95 & 1.26 & 2.51 & 0.3834 & 0.2612 & 0.009 \\
\hline R0175F12 & no hits & 0.85 & 0.64 & 0.51 & 1.44 & 2.93 & 7.57 & 0.2244 & 0.0196 & 0.0023 \\
\hline $\mathrm{R} 0025 \mathrm{C} 08$ & archain/delta-COP homolog - rice & 1.10 & 1.16 & 0.91 & 0.90 & 1.40 & 2.28 & 0.3324 & 0.0439 & 0.0005 \\
\hline R0008B09 & aspartic proteinase & 1.01 & 1.25 & 1.15 & 1.21 & 1.88 & 2.20 & 0.0961 & 0 & 0.0001 \\
\hline R0010F11 & aspartic proteinase & 1.06 & 1.31 & 0.85 & 1.34 & 2.14 & 3.86 & 0.0709 & 0.0089 & 0.0024 \\
\hline R0124A09 & oryzain gamma & 0.85 & 1.04 & 0.86 & 1.33 & 1.18 & 2.79 & 0.0395 & 0.1045 & 0.0011 \\
\hline R0018H11 & syntaxin SYP132 & 1.16 & 1.15 & 0.69 & 0.96 & 1.48 & 3.63 & 0.7234 & 0.0667 & 0.002 \\
\hline R0021H10 & $\begin{array}{l}\text { High-glucose-regulated protein } 8 \\
\text { (NY-REN-2 antigen) }\end{array}$ & 1.03 & 1.21 & 0.98 & 0.86 & 1.35 & 2.16 & 0.0531 & 0.0629 & 0.0006 \\
\hline $\mathrm{R} 0281 \mathrm{C} 08$ & expressed protein & 1.47 & 1.06 & 0.99 & 0.75 & 1.85 & 2.22 & 0.2736 & 0.0019 & 0.0042 \\
\hline R0310F12 & expressed protein & 1.18 & 1.21 & 0.53 & 1.25 & 1.62 & 4.41 & 0.054 & 0.0263 & 0.0033 \\
\hline R0507G02 & similarity to high-glucose-regulated protein & 1.00 & 1.13 & 1.30 & 1.03 & 1.58 & 2.04 & 0.7466 & 0.0074 & 0.0009 \\
\hline \multicolumn{11}{|l|}{ Group IV } \\
\hline R0049C03 & putative aspartate kinase & 1.01 & 1.21 & 1.40 & 0.92 & 0.28 & 0.49 & 0.6879 & 0.0002 & 0.0109 \\
\hline R0297G05 & Serine carboxypeptidase & 1.69 & 1.13 & 0.87 & 0.50 & 0.37 & 0.64 & 0.0163 & 0.006 & 0.0034 \\
\hline R0331D04 & AT3g15480/MJK13_14 & 0.95 & 0.93 & 1.27 & 0.91 & 0.47 & 0.59 & 0.4237 & 0.0013 & 0.1864 \\
\hline R0370D11 & uroporphyrinogen decarboxylase & 1.43 & 0.91 & 0.85 & 0.71 & 0.41 & 0.57 & 0.1938 & 0.0004 & 0.0477 \\
\hline R0489B03 & $\begin{array}{l}\text { mini-chromosome maintenance } \\
\text { protein MCM6 }\end{array}$ & 1.78 & 1.06 & 0.83 & 0.54 & 0.45 & 0.79 & 0.0073 & 0.0013 & 0.0531 \\
\hline R0154A07 & $\begin{array}{l}\text { chlorophyll a/b-binding protein } \\
\text { CP26 precursor }\end{array}$ & 1.00 & 0.18 & 0.38 & 0.97 & 2.68 & 1.75 & 0.8408 & 0.0011 & 0.0059 \\
\hline R0436G05 & Peptidyl-prolyl cis-trans isomerase & 1.40 & 1.06 & 1.27 & 0.84 & 0.44 & 0.66 & 0.6572 & 0.0007 & 0.0363 \\
\hline R0161E02 & hypothetical protein & 1.33 & 1.01 & 1.07 & 0.77 & 0.49 & 0.61 & 0.4167 & 0 & 0.0376 \\
\hline R0296E01 & phi-1 & 1.28 & 0.89 & 0.82 & 0.66 & 0.49 & 0.75 & 0.1572 & 0.0013 & 0.093 \\
\hline \multicolumn{11}{|l|}{ Group V } \\
\hline R0252E01 & probable protein kinase & 1.07 & 0.33 & 0.63 & 0.79 & 0.97 & 0.48 & 0.301 & 0.8936 & 0.0163 \\
\hline R0360G08 & receptor protein kinase zmpk1 precursor & 1.13 & 0.70 & 0.89 & 0.72 & 0.63 & 0.47 & 0.0993 & 0.1199 & 0.0105 \\
\hline R0070F03 & sucrose-UDP glucosyltransferase 2 & 0.73 & 0.46 & 0.58 & 1.06 & 0.86 & 0.46 & 0.7574 & 0.647 & 0.06 \\
\hline R0131E05 & $\begin{array}{l}\text { S-adenosyl-methionine-sterol-C } \\
\text {-methyltransferase }\end{array}$ & 0.78 & 0.59 & 0.52 & 1.38 & 0.46 & 0.47 & 0.0123 & 0.0299 & 0.0068 \\
\hline R0250H11 & tryptophan synthase, beta subunit & 0.91 & 0.86 & 1.00 & 0.91 & 0.48 & 0.50 & 0.0481 & 0.0054 & 0.0079 \\
\hline R0272A08 & Sucrose synthase, putative & 1.04 & 0.48 & 0.87 & 0.66 & 0.93 & 0.44 & 0.225 & 0.7271 & 0.0006 \\
\hline R0171D04 & no hits & M & 1.13 & 1.42 & M & 1.51 & 0.40 & M & 0.1289 & 0.059 \\
\hline R0178F01 & TAZ zinc finger, putative & 1.41 & 1.31 & 0.95 & 0.54 & 0.58 & 0.49 & 0.1235 & 0.0463 & 0.0027 \\
\hline $\mathrm{R} 0252 \mathrm{C} 12$ & $\begin{array}{l}\text { Zinc finger, C3HC4 type (RING finger), } \\
\text { putative }\end{array}$ & 1.35 & 0.56 & 0.82 & 0.55 & 0.84 & 0.46 & 0.0944 & 0.203 & 0.0002 \\
\hline R0245A09 & proliferating cell nuclear antigen (pcna) & 1.01 & 0.71 & 1.02 & 0.82 & 0.44 & 0.35 & 0.0316 & 0.0194 & 0.0137 \\
\hline
\end{tabular}


had been proved to play very important roles in salt tolerance of rice or other plants, such as $O s C D P K 7$ [26, 27], the protein phosphatase $2 \mathrm{C}$ gene [28-30], the $S Y P$ gene [33] and glyoxalase gene [31] (Tab. 3). These observations seem to indicate that failure of expressional regulation of these salt tolerance genes may govern at least part of the salt hypersensitivity seen in IR28.

However, we also found a number of genes that were regulated to a higher degree in salt-stressed IR28 than in salt-stressed Nona (Tab. 3). This group included SalT (R0123D10), encoding a salt-induced lectin-like protein (Tab. 3) [34]. Previous work showed that treatment with trehalose improved rice saline tolerance but suppressed SalT up-regulation, while proline treatment increased the growth inhibition of salt-treated rice and up-regulated SalT [35]. These previous observations and our results may suggest that lower SalT expression in Nona might be a sign of tolerance to salt stress. In addition, the SalT low level expression in Nona could be mediated by trehalose, since genes encoding trehalose synthases (e.g. the TPP gene, R0049E02; Tab. 3) were up-regulated more in Nona than in IR28 (Suppl. 2).

\section{DISCUSSION}

\section{The microarray analysis reliably detected positive genes}

Although microarray has been shown to be a powerful tool for researching transcriptome changes, controlling data quality remains a challenge. To control against negative results due to individual differences, our samples were pooled from more than 30 seedlings. To examine whether our pooling protocol impacted the microarray results, we compared the results of two hybridizations with the same RNA sample, and those of two independent RNA samples taken under identical conditions. Our results showed that although there was some biological variation, the data interpretation was not affected, particularly when we used stringent criteria for screening positive ESTs.

Screening of differentially expressed genes has long been a topic of great interest and a particular challenge for microarray analysis. In the early years of microarray research, "positive" genes were often identified by a dogmatic criterion, such as a 1.5-fold, 2-fold, 3-fold or even 5 -fold change. This method can not resolve the conflict of type I and type II errors. In recent years, increasing numbers of researchers have incorporated statistical hypothesis testing into their gene screening methodologies. The statistical methods that have most commonly been used are a one-class $t$-test or SAM (Significance Analysis of Microarrays). However, concerns about the limitations of these methods have been raised. For example, the oneclass $t$-test applies statistics to evaluate whether there is a significant difference: $t=\mathrm{M}_{\text {ave }} /\left(s / n^{1 / 2}\right)$, where $\mathrm{M}_{\text {ave }}$ is the average of Log2 ratios of replicates, $s$ represents the standard deviation and $n$ represents the number of replicates. Although the one-class $t$-test is generally a good selection for statistics analysis, a gene that is not differentially regulated, that is its $M_{\text {ave }}$ is near 0 , could appear to be significant if its $M$ values across replicates are very near to one another. This type of error is more likely to occur when there are few replicates. Microarray replicate numbers however are limited by cost.

To limit findings of false positive genes, we not only performed a one-class $t$-test for positive gene screening in Nona shoot and a two-group $t$-test for detecting those genes that are differentially regulated between Nona and IR28, we also applied a dogmatic criterion (2-fold). This strategy enabled us to achieve a marked decrease in false hits. Although this strategy for screening positive genes or detecting differential regulation genes may increase the rate of false negative determinations and therefore result in some important genes being missed, for the present aims it was most important in our view to reduce the false positive level and to thereby minimize the influence of false hitting upon data interpretation. Our results were further validated by Northern blotting and semi-quantitative RT-PCR experiments for 11 randomly selected salt-responsive genes identified by our microarray analysis.

\section{Identification of numerous novel, previously uniden- tified salt response genes}

Plant salt tolerance is a complex trait controlled by multiple factors. Although a number of salt tolerance-related genes have been cloned, we do not have a full understanding of the plant mechanisms used for coping with salt stress. In Saccharomyces cerevisiae, $\sim 8 \%$ of the entire genome was found to be affected during salt stress [36]. Even if a similar degree of expression change occurs in rice, there might be $\sim 5,000$ genes responding to salt stress. This logic predicts that there should be a large number of as yet unknown salt response genes, although several excellent studies have previously revealed many salt response genes in rice $[14,19]$ or in other plants [15-18, 20-21]. Here, we identified $\sim 450$ salt response genes in Nona rice. However, of the identified genes, only $175(\sim 40 \%)$ had been reported previously in rice or other plants, while $325(\sim 60 \%)$ genes were newly identified salt responsive genes (Tab. 1). Thus it appears that there are a large number of genes that are involved in salt response in rice.

There are two factors that may have contributed to the identification of many novel salt response genes in this study. The first is that there was a greater number and greater variety of cDNA sequences contained in the microarray used in this study than used in those previous 
studies, which were all smaller than 10k (Tab. 1) [14-21]. Secondly, there is spatio-temporal specificity in the induction of salt response genes. For example, in Arabidopsis the salt response genes in shoot might differ from those in root [16]. Our findings suggest that great differences also exist between rice shoot and root. We found that $54.4 \%$ (31 of 57) of salt response genes previously identified in whole rice plant were also found in this study [19], while only $19.6 \%$ (42 of 214) of those in rice root were identified in this study (Tab. 1) [14]. Comparison between the genes identified in this study and those of previous studies in barley yields a similar consistency (Tab. 1). Also consistent with previous studies, we found that most of the identified salt response genes were expressed in a transient pattern (Tab. 2) [14-15, 18]. This study used shoots of a salt tolerant rice variety and different organs from those of previous studies as research material. Thus it should not be surprising given the spatio-temporal specificity of salt response gene induction that our experiments would reveal many novel salt response genes are identified.

\section{Newly identified genes could be candidates for salt tolerance engineering}

Some of the previously reported genes, such as those encoding GlyI, OsCDPK7, and family members of protein phosphatase $2 \mathrm{C}$, syntaxin and trehalose synthase, had been previously identified through classical and reveres genetics, and are thought to be good candidates for engineering salt tolerance in crops. Some classical salt response genes, such as the DREBs [8-11] and HVA1 [12], have already been used to engineer salt-tolerant plants. The results from these engineered plants have suggested that salt-induced genes have potential value for improving plant stress adaptation mechanisms and improving salt tolerance in crops. Thus, further examination of the newly identified salt response genes will be warranted to determine if any or all could be used as novel candidates for salt tolerance engineering.

\section{Some salt tolerance-associated genes may be consti- tutively expressed in Nona}

We observed a slightly smaller percentage of overall genes regulated in response to salt treatment in Nona (5\%) versus the proportions identified in yeast ( $8 \%)$ and maize $(11 \%)[18,22,23]$. This could be because we examined fewer time points than the previous studies. Alternatively, it is possible that some of the genes that are salt-induced in other plants are constitutively over expressed in Nona. This latter explanation seems likely, as tolerant varieties often constitutively express some of the tolerance-related genes [20]. This hypothesis could be directly addressed by performing transcriptome analysis of a salt sensitive rice line and Nona without salt stress. However, considered many phenotypes between Nona and other rice lines are different, the identified differentially expressed genes may be not all related with salt tolerance.

\section{Multiple regulation pathways may be involved in salt stress}

A previous study reported that there were genes in rice root that responded after just 15 min of salt shock [14]. Although such quickly responding genes were few in number, they may be critically involved in transcriptome reprogramming under salt stress. In the previous report, there were 6 genes upregulated $(\log -10$ ratio $>0.2)$ and 9 genes downregulated $(\log -10$ ratio $<-0.2)$ in the Pokkali root after $15 \mathrm{~min}$ of salt shock [14]. However, with the exception of $O s C D P K 7$, the functions of most of these were not known [26-27].

Here we examined the transcriptome of Nona shoot after 20 min of salt shock to capture the induction of instantaneous response genes. Contrary to the previous study, we found that all of the 28 identified salt instantaneous response genes in Nona shoot were upregulated (Suppl. $1)$. These findings suggest that the salt induced transcriptome reprogramming and gene regulation pathways in shoot differ from that in root. Interestingly, further analysis of this group of genes, which were mainly clustered into Group I, showed that the majority of them were transcription factors and kinases (Tab. 2). Thus kinase and transcription activation are implicated as very early events of transcriptome reprogramming of rice shoot under salt stress. Furthermore, these multiple TFs are comparable with DREBs/CBFs, RD22BP and AtMyb, which act as early salt response genes by controlling the downstream delayed response genes [36]. Researchers believe that there are multiple regulatory pathways involved in environmental stress acclimation [6]. Consistent with this hypothesis, Tran et al. found three ERDI (a dehydration stress response gene) upstream regulators in Arabidopsis, all of which belong to the NAC transcription factor family and target abiotic stress response genes [24]. The OsNAC8 transcription factor we identified as a salt-responsive gene in Nona (Suppl. 1) could be an ortholog of these genes. In addition, our clustering analysis revealed that a number of genes clustered into Groups II and III, including Clp, DnaJ and GlyI, possess NAC core DNA binding sites in their promoter regions (data not shown). Thus, our results are consistent with the notion that the rice transcriptome is regulated via multiple pathways during salt stress.

\section{Many of the salt tolerance genes are rapidly induced in Nona}

The adaptive response of plants during salt stress was 
believed to include three aspects: ion homeostasis, damage control and growth regulation [36]. At the gene expression level, these factors should be controlled by the regulation of three functional gene categories: transport, cell defense and detoxification, and metabolism and energy (photosynthesis). Our results showed that the salttolerant Nona line showed rapid induction of the cell defense and detoxification genes following salt treatment. Within 3 h, 76.5\% of the identified genes in this category had been up-regulated (1 in Group I, 37 in Group II and 1 in Group III) (Tab. 2, Suppl. 1). This rapid response is vital to salt tolerance, because high salt may lead to rapid stress damage that quickly becomes irreversible. Our observation that the detoxification category predominated in Group II suggests that damage repair is a vital cellular process in salt-tolerant rice shoots $3 \mathrm{~h}$ after salt stress treatment. These genes function in every aspect of damage control or repair, playing roles in removal of ROS and other stress induced toxins, repair of proteins and DNA, protection against enzyme activity, and maintenance of osmotic homeostasis. Some of these genes (Tpp, Clp, DnaJ and Glys) were differentially regulated in IR28 versus Nona, indicating that their decreased expression in IR28 shoots may contribute to the hypersensitivity of this line to salt (Tab. 3, Suppl. 2). Interestingly, 6 other detoxification genes were down-regulated in Nona (1 in Group IV and 5 in Group V) (Tab. 2), suggesting that they may play non-detoxification roles in salt-stressed shoots. Furthermore, we identified rapid induction of multiple transport-related genes, which are likely related with ion homeostasis. Almost all (26 of 28) transport-related genes responded within $3 \mathrm{~h}$ of treatment (Suppl. 1); 60.71\% were clustered into Group II and $21.43 \%$ were clustered into Group IV. Finally, the rapid down-regulation observed in the photosynthesis- and metabolism-related genes likely reflects the growth inhibition observed in salt-stressed plants.

\section{Crosstalk appears to occur between the salt stress and senescence pathways, and the abiotic and biotic stress signaling pathways}

When plants are exposed to environmental stress, they often show senescent phenotypes such as leaf scorch. Previous work has shown that pathogen infection activates genes that are normally induced during senescence, suggesting that senescence may be involved with plant defense [37]. Here, we found that salt stress also induced multiple senescence-associated genes, suggesting that salt stress may induce leaf senescence. This response could help the plant adapt to salt stress in a number of ways, including decreased transpiration in senescent leaves, diversion of energy and food resources to the tender leaves and SAM (shoot apical meristem), and protection of important organs by accumulation of toxic ions in the senescent leaves. Interestingly, we also found that some disease resistance- and defense-associated proteins were affected by salt treatment of Nona shoots, further indicating that crosstalk may occur between the salt stress and biotic stress pathways. While such crosstalk has been reported previously [38], this is the first time that up-regulation of $\mathrm{R}$ genes (resistance genes) has been reported in response to salt stress.

\section{The shoot transcriptomes differ between salt-sensi- tive and -tolerant rice lines}

Finally, we compared the salt response gene expression patterns of salt-sensitive and -tolerant rice lines during salt stress to better elucidate the mechanisms of plant adaptations to salt stress. Previous research on the root transcriptomes of salt-sensitive and -tolerant rice varieties (Pokkali and IR29) during salt stress revealed that expression of the salt response genes was disordered and delayed in the salt-sensitive IR29 line [14]. However, the present work is the first report of differences between the shoot transcriptomes of salt-sensitive and -tolerant lines, in this case IR28 and Nona, respectively.

Consistent with the previous report in roots, we found that the shoot transcriptome of salt-stressed IR28 was greatly disordered in comparison with that of salt-stressed Nona. About $70 \%$ of the salt responsive ESTs showed transcription-level differences between IR28 and Nona following salt stress. Some of the differentially expressed genes have been previously associated with plant salt tolerance, including the genes encoding glyoxalase [31], syntaxin [33], protein phosphatase 2C [28-30] and OsCDPK7 [26-27]. As it is likely that these differentially expressed genes are generally involved in salt tolerance/ sensitivity, they should be considered as good candidates for future engineering efforts. Interestingly, we found that the transcriptomes of IR28 and Nona differed more dramatically at $20 \mathrm{~min}$ and $24 \mathrm{~h}$ after salt treatment versus the $3 \mathrm{~h}$ time point. This seems inconsistent with the concept of early response genes controlling delayed response genes during salt stress [36]. One possible explanation for the difference at $20 \mathrm{~min}$ is that the immediate response genes are delayed in IR28 relative to Nona; this phenomenon has been seen in the root of another stress-sensitive variety [14]. Although the genes regulated at $3 \mathrm{~h}$ might also be delayed, the difference could be lessened by the spans of the response. Under this paradigm, the greater difference at $24 \mathrm{~h}$ might mainly result from upstream cascades that are activated differently in IR28 versus Nona.

In conclusion, this report identified 486 salt response ESTs in rice shoot, and about $60 \%$ of these genes were 
newly identified, which suggests that a large number of salt response genes had previously remained unidentified. Our findings may provide more candidate genes for engineering salt-tolerant crops. Further analysis of the ESTs revealed multiple regulation pathways in addition to $\mathrm{CBF}$ pathway might be involved in reprogramming of saltstressed rice, and the rapid response of detoxification-, protectant- and transport-related genes might contribute to the high level salt tolerance of Nona. Transcriptome analysis of Nona also indicated that crosstalk might occur between salt stress and leaf senescence, as well as between salt stress and biotic stress. Comparing of transcriptomes of salt-tolerant and -sensitive varieties indicated the different transcriptome and failure response of vital salt tolerance-related genes might be important reasons of the sensitivity of IR28. These findings may greatly contribute to a better understanding of rice tolerance to salt stress.

\section{ACKNOWLEDGEMENTS}

We are grateful to Guoliang WANG (Department of Plant Pathology, Ohio State University) for review. We also thank Jian Feng HUANG, Xu Ping FU (United Gene Ltd., China), Yu Chen CHEN and Qi WANG (Shanghai Biochip Corp., China) for their help with technical support and statistical analysis, and Wei HUANG and Mei Zhen ZHU for technical assistance. This work was supported by the Ministry of Science and Technology of China (JY03-A-10, 2002AA2Z1003 and 2003CB114303), and Science and Technology Committee of Shanghai Municipality (03DJ14016).

\section{Received, Jun 17, 2005}

Revised, Sep 16, 2005

Accepted, Oct 18, 2005

\section{REFERENCES}

1 Boyer JS. Plant productivity and environment. Science 1982; 218:443-8.

2 Chinnusamy V, Schumaker K, Zhu JK. Molecular genetic perspectives on cross-talk and specificity in abiotic stress signalling in plants. J Exp Bot 2004; 55:225-36.

3 Shi H, Lee BH, Wu SJ, Zhu JK. Overexpression of a plasma membrane $\mathrm{Na}^{+} / \mathrm{H}^{+}$antiporter gene improves salt tolerance in Arabidopsis thaliana. Nat Biotechnol 2003; 21:81-5.

4 Shinozaki K, Yamaguchi-Shinozaki K. Molecular responses to dehydration and low temperature: Differences and cross-talk between two stress signaling pathways. Curr Opin Plant Biol 2000; 3:217-23.

5 Seki M, Narusaka M, Abe H, et al. Monitoring the expression pattern of 1300 Arabidopsis genes under drought and cold stresses by using a full-length cDNA microarray. Plant Cell 2001; 13:6172.

6 Fowler S, Thomashow MF. Arabidopsis transcriptome profil- ing indicates that multiple regulatory pathways are activated during cold acclimation in addition to the CBF cold response pathway. Plant Cell 2002; 14:1675-90.

7 Maruyama K, Sakuma Y, Kasuga M, et al. Identification of coldinducible downstream genes of the Arabidopsis DREB1A/CBF3 transcriptional factor using two microarray systems. Plant J 2004; 38:982-93.

8 Jaglo-Ottosen KR, Gilmour SJ, Zarka DG, Schabenberger O, Thomashow MF. Arabidopsis CBF1 overexpression induces COR genes and enhances freezing tolerance. Science 1998; 280: 104-6.

9 Liu Q, Kasuga M, SakumaY, et al. Two transcription factors, DREB1 and DREB2, with an EREBP/AP2 DNA binding domain separate two cellular signal transduction pathways in drought- and low-temperature-responsive gene expression, respectively, in Arabidopsis. Plant Cell 1998; 10:1391-406.

10 Lee JT, Prasad V, Yang PT, et al. Expression of Arabidopsis $\mathrm{CBF} 1$ regulated by an $\mathrm{ABA} /$ stress promoter in transgenic tomato confers stress tolerance without affecting yield. Plant Cell Environ 2003; 26:1181-90.

11 Dubouzet JG, Sakuma Y, Ito Y, et al. OsDREB genes in rice, Oryza sativa L., encode transcription activators that function in drought-, high-salt- and cold-responsive gene expression. Plant J 2003; 33:751-63.

12 Xu D, Duan X, Wang B, et al. Expression of a Late Embryogenesis Abundant Protein Gene, HVA1, from Barley Confers Tolerance to Water Deficit and Salt Stress in Transgenic Rice. Plant Physiol 1996; 110:249-57.

13 Lin HX, Zhu MZ, Yano M, et al. QTLs for $\mathrm{Na}^{+}$and $\mathrm{K}^{+}$uptake of the shoots and roots controlling rice salt tolerance. Theor Appl Genet 2004; 108:253-60.

14 Kawasaki S, Borchert C, Deyholos M, et al. Gene expression profiles during the initial phase of salt stress in rice. Plant Cell 2001; 13:889-906.

15 Seki M, Narusaka M, Ishida J, et al. Monitoring the expression profiles of 7000 Arabidopsis genes under drought, cold and highsalinity stresses using a full-length cDNA microarray. Plant J 2002; 31:279-92.

16 Kreps JA, Wu Y, Chang HS, et al. Transcriptome changes for Arabidopsis in response to salt, osmotic, and cold stress. Plant Physiol 2002; 130:2129-41.

17 Oztur ZN, Talame V, Deyholos M, et al. Monitoring large-scale changes in transcript abundance in drought- and salt-stressed barley. Plant Mol Biol 2002; 48:551-73.

18 Wang H, Miyazaki S, Kawai K, et al. Temporal Progression of Gene Expression Responses to Salt Shock in Maize Roots. Plant Mol Biol 2003; 52: 873-91.

19 Rabbani MA, Maruyama K, Abe H, et al. Monitoring expression profiles of rice genes under cold, drought, and high-salinity stresses and abscisic acid application using cDNA microarray and RNA gel-blot analyses. Plant Physiol 2003; 133:1755-67.

20 Taji T, Seki M, Satou M, et al. Comparative genomics in salt tolerance between Arabidopsis and aRabidopsis-related halophyte salt cress using Arabidopsis microarray. Plant Physiol 2004; 135:1697-709.

21 Takahashi S, Seki M, Ishida J, et al. Monitoring the expression profiles of genes induced by hyperosmotic, high salinity, and oxidative stress and abscisic acid treatment in Arabidopsis cell culture using a full-length cDNA microarray. Plant Mol Biol 
2004; 56:29-55

22 Yale J, Bohnert HJ. Transcript expression in S. cerevisiae at high salinity. J Biol Chem 2001; 276:15996-6007.

23 Posas F, Chambers JR, Heyman JA, et al. The transcriptional response of yeast to salt stress. J Biol Chem 2000; 275:17249-55.

24 Tran LS, Nakashima K, Sakuma Y, et al. Isolation and functional analysis of Arabidopsis stress-inducible NAC transcription factors that bind to a drought-responsive cis-element in the early responsive to dehydration stress 1 promoter. Plant Cell 2004; 16:2481-98.

25 Urao T, Katagiri T, Mizoguchi T, et al. Two genes that encode c a $\left({ }^{2+}\right)$-dependent protein kinases are induced by drought and high-salt stresses in Arabidopsis thaliana. Mol Gen Genet 1994; 244:331-40.

26 Saijo Y, Kinoshita N, Ishiyama $\mathrm{K}$, et al. A Ca(2+)-dependent protein kinase that endows rice plants with cold- and salt-stress tolerance functions in vascular bundles. Plant Cell Physiol 2001; 42:1228-33.

27 Saijo Y, Hata S, Kyozuka J, Shimamoto K, Izui K. Over-expression of a single $\mathrm{Ca} 2+$-dependent protein kinase confers both cold and salt/drought tolerance on rice plants. Plant J 2002; 23:319-27.

28 Ohta M, Guo Y, Halfter U, Zhu JK. A novel domain in the protein kinase SOS2 mediates interaction with the protein phosphatase 2C ABI2. Proc Natl Acad Sci U S A 2003; 100:11771-6.

29 Delumeau O, Dutta S, Brigulla M, et al. Functional and structural characterization of RsbU, a stress signaling protein phosphatase 2C.J Biol Chem 2004; 279:40927-37.
30 Leonhardt N, Kwak JM, Robert N, et al. Microarray expression analyses of Arabidopsis guard cells and isolation of a recessive abscisic acid hypersensitive protein phosphatase $2 \mathrm{C}$ mutant. Plant Cell 2004; 16:596-615.

31 Singla-Pareek SL, Reddy MK, Sopory SK. Genetic engineering of the glyoxalase pathway in tobacco leads to enhanced salinity tolerance. Proc Natl Acad Sci U S A 2003; 100:14672-7.

32 Elizabeth $\mathrm{AB}$, Julia BS, Elizabeth W. In: Buchanan, BB, Gruissem, W, Jones RL Eds. Biochemistry and molecular biology of plants. Plenum Press: American society of plants philologists Rockville 2000:1168-9.

33 Zhu J, Gong Z, Zhang C, et al. OSM1/SYP61: a syntaxin protein in Arabidopsis controls abscisic acid-mediated and non-abscisic acid-mediated responses to abiotic stress. Plant Cell 2002; 14: 3009-28.

34 Claes B, Dekeyser R, Villarroel R, et al. Characterization of a rice gene showing organ-specific expression in response to salt stress and drought. Plant Cell 1990; 2:19-27.

35 Garcia AB, Engler J, Iyer S, et al. Effects of Osmoprotectants upon NaCl Stress in Rice. Plant Physiol 1997; 115:159-69.

$36 \mathrm{Zhu}$ JK. Salt and drought stress signal transduction in plants. Annu Rev PlantBiol 2002; 53:247-73.

37 Quirino BF, Noh YS, Himelblau E, Amasino RM. Molecular aspects of leaf senescence. Trends Plant Sci 2000; 5:278-82.

38 Xiong L, Yang Y. Disease resistance and abiotic stress tolerance in rice are inversely modulated by an abscisic acid-inducible mitogen-activated protein kinase. Plant Cell 2003; 15:745-59.

Edited by Bernd MUELLER-ROEBER 